\title{
Current Challenge: Endoscopic Submucosal Dissection of Superficial Non-ampullary Duodenal Epithelial Tumors
}

Kazuya Akahoshi, MD, $P h D^{1,2, *}{ }^{\circ}$

Masaru Kubokawa, MD, PhD ${ }^{2}$

Kazuki Inamura, $M D^{2}$

Kazuaki Akahoshi, MD

Yuki Shiratsuchi?

Shinichi Tamura ${ }^{3}$

\author{
Address \\ ${ }^{*}, 1$ Endoscopy Center, Aso Iizuka Hospital, 3-83 Yoshio town, Iizuka, 820-8505, \\ Japan \\ Email:kakahoshi2@aol.com \\ 2Department of Gastroenterology, Aso Iizuka Hospital, Iizuka, 820-8505, Japan \\ ${ }^{3}$ Faculty of Medical Engineering, Aso Iizuka Hospital, Iizuka, 820-8505, Japan
}

Published online: 26 0ctober 2020

(C) The Author(s) 2020

\section{Electronic supplementary material}

This article is part of the Topical Collection on Upper Gastrointestinal Cancers

The online version of this article (https://doi.org/10.1007/s11864-020-00796-y) contains supplementary material, which is available to authorized users.

Keywords Early duodenal cancer • Duodenal adenoma - Endoscopic submucosal dissection - Endoscopic mucosal resection

\section{Opinion statement}

With the widespread use of esophagogastroduodenoscopy in recent years, the detection rate of superficial non-ampullary duodenal epithelial tumors (SNADETs) is increasing. Most SNADETs are early-stage adenocarcinoma or benign conditions, including adenoma. Therefore, endoscopic resection is desirable from the perspective of quality of life. However, endoscopic resection for SNADETs has not yet been established. Endoscopic submucosal dissection (ESD) is the most promising method for the treatment of SNADETs, because ESD provides a high rate of en bloc resection and a low rate of recurrence regardless of the tumor size. However, the difficulty of the procedure and a high rate of severe adverse events including perforation and bleeding have become major problems. 
Various preventive countermeasures for adverse events, such as use of specific devices, endoscope stabilization methods, and endoscopic closure of the post-ESD ulcer using clips, are reported to reduce the risk of the adverse events of ESD for SNADETs. This article reviews and highlights the current state of ESD for SNADETs and new challenges towards safe and effective ESD.

\section{Introduction}

Widespread use of esophagogastroduodenoscopy (EGD) has resulted in increased detection of superficial nonampullary duodenal epithelial tumors (SNADETs) [1・, 2, 3]. SNADETs include early-stage adenocarcinoma and benign conditions including adenoma, but the diagnostic accuracy of endoscopic biopsy for SNADETs is low. Furthermore, because the duodenal wall is thin, the biopsy procedure itself can cause unexpected fibrosis and make subsequent endoscopic resection difficult $[4,5]$. Therefore, if SNADETs are detected, endoscopic total resection is recommended to obtain conclusive histological diagnosis and complete cure. However, endoscopic resection for
SNADETs has not yet been established. Conventional endoscopic mucosal resection (EMR) is the standard method, but its recurrence rate is high at 5-37\% [6-10]. Piecemeal EMR is performed for broad lesions but it has a high risk of perforation [11]. Conversely, endoscopic submucosal dissection (ESD) can achieve complete resection regardless of lesion size, but it is also accompanied by high rates of adverse events [12-18, 19••, 20, 21]. Problematic major adverse events are perforation and bleeding. Many countermeasures including new devices and methods have been applied, and the incidence of adverse events is gradually decreasing.

\section{Clinical features of SNADETs}

SNADETs are defined as lesions that are limited to the mucosa or submucosa, and include adenoma and adenocarcinoma. In previous epidemiological surveys, SNADETs were rare [22], and primary duodenal cancers accounted for only about $0.5 \%$ of all gastrointestinal malignancies [23]. SNADETs are reported to be detected in less than $0.4 \%$ of patients who undergo EGD [24, 25], but recently, they have been detected more frequently because of advances in endoscopy $[1 \bullet]$. Advanced duodenal cancer has a poor prognosis, and surgical treatment is associated with a high rate of morbidity and mortality [26-28]. Goda et al. [1•] reported that the rate of lymph node metastasis in early duodenal cancers was $0 \%$ in intramucosal cancers and $10 \%$ in submucosal cancers. Intramucosal SNADETs including mucosal cancer and adenoma are a good indication for endoscopic resection, whereas submucosal cancer is an indication for surgical resection with lymph node dissection. Therefore, early diagnosis and treatment of SNADETs are important. Typical endoscopic findings of duodenal adenoma with high-grade atypia or early cancer are tumor diameter larger than $5 \mathrm{~mm}$ and red color [1•]. Furthermore, macroscopic types 0-I (protruded type) or 0-IIa + IIc (flat elevated type with shallow depression) with red color are reported as endoscopic features of duodenal submucosal cancer $[1 \bullet]$. These endoscopic diagnostic criteria are expected to increase the 
EGD detection rates of SNADETs at the stage of adenoma with high-grade atypia or early cancer. This may allow us to improve the poor prognosis of duodenal cancer as well as quality of life, because early detection by EGD promotes less invasive and radical treatment such as endoscopic resection.

\section{EMR using the snare}

At present, conventional EMR using a snare is considered a standard endoscopic therapy for SNADETs, although there are some problems [29]. Reported en bloc resection rate and R0 resection rate of EMR using the snare for SNADETs range from 79 to $98 \%$ and from 53 to $62 \%$, respectively [6-10, 19••]. In reported long-term outcome, recurrence rate ranges from 5 to $37 \%$ [6-10, 19••]. IntraEMR perforation rate, delayed perforation rate, and delayed bleeding rate are 0 $2 \%, 0-4 \%$, and $0-15 \%$, respectively $[6-11,19 \bullet \bullet]$. Recently, safer resection methods such as cold snare polypectomy (CSP) [30] and underwater EMR (UWEMR) have been developed [31]. CSP is an easy technique for small duodenal lesions and is expected to reduce the risk of delayed perforation or bleeding because there is no electrothermal damage induced by the highfrequency current. Reported R0 resection rate and perforation rate for small duodenal adenoma less than $6 \mathrm{~mm}$ (25 patients) were $68 \%$ and $0 \%$, respectively [30]. UWEMR developed by Binmoeller et al. [31] is a unique technique that resects the target lesions underwater by snare without lifting them with submucosal injections. Because the gastrointestinal tract is not stretched by air inflation, it is expected that capturing a target lesion of up to $2 \mathrm{~cm}$ in water is easier in the duodenum. Reported R0 resection rate and perforation rate of small duodenal adenoma smaller than $20 \mathrm{~mm}$ (30 patients) were $61 \%$ and $0 \%$, respectively [32]. A large Japanese multicenter retrospective study (1397 patients) showed that R0 resection rates and perforation rates of EMR, CSP + UWEMR, ESD, and laparoscopic-endoscopic cooperative surgery (LECS) were $53 \%$ and $2.3 \%, 44 \%$ and $3.4 \%, 75 \%$ and $16.2 \%$, and $74 \%$ and $7.7 \%$, respectively $[19 \bullet \bullet$. At present, EMR using a snare, including CSP and UWEMR, is recognized as an easy and safe technique for small SNADETs. However, since EMR is a resection method performed by narrowing down the snare, it is difficult to control the excision line and it frequently leads to piecemeal EMR. If there is recurrence after piecemeal EMR, because of severe fibrosis caused by EMR, excision is difficult, even with ESD, and the risk of perforation is high. Incomplete excision with EMR can create a situation that requires invasive surgery including pancreaticoduodenectomy. Theoretically, EMR is considered an alternative to ESD until a system that can safely enforce ESD is established.

Compared with EMR for early gastrointestinal tract cancer, ESD has considerable advantages regarding the en bloc resection rate, $\mathrm{R} 0$ resection rate, and rate of local recurrence [33-38]. EMR has gradually been replaced by ESD. EMR resects the lesion by narrowing down the oval snare; therefore, it is difficult to seize the tumor completely according to the shape and size of the lesion, and the en bloc resection rate is low [33]. In contrast, ESD resects targeted tissue little by little using a knife or scissors (Video 1) while observing the demarcation line of the lesion with an 
endoscope (Fig. 1); thus, ESD provides high R0 resection rates and low local recurrence rate, irrespective of tumor size and shape. ESD has become a standard treatment for superficial esophageal, gastric, and colorectal tumors in Japan. Reported en bloc resection rate and R0 resection rate of ESD for SNADETs range from 67 to $100 \%$ and from 29 to $90 \%$, respectively (Table 1) [8, 12-18, 19••, 20, 21]. In reported long-term outcome, the recurrence rate of ESD for SNADETs was $0 \%[8,13-15,17,18,20]$. The en bloc resection rate of ESD is higher than that of EMR, which contributes to accurate histological evaluation of the resected specimen, and high R0 resection rate and low local recurrence rate [8, 15, 39]. However, ESD for SNADETs is technically demanding because of organ specificity of the duodenum and it is reported to have a high incidence of severe, including fatal, adverse events [40]. At present, SNADET is a rare disease, and ESD techniques for duodenal tumors have not yet been established and fully evaluated for their effectiveness and safety. The above clinical outcomes for duodenal ESD were mainly reported by skilled endoscopists at high-volume centers in Asia including Japan $[12-18,19 \bullet \bullet, 20,21]$.

\section{Adverse events of ESD for SNADETs}

ESD is technically more difficult for duodenal tumors than tumors of other organs, with a higher rate of severe adverse events. The difficulty of duodenal

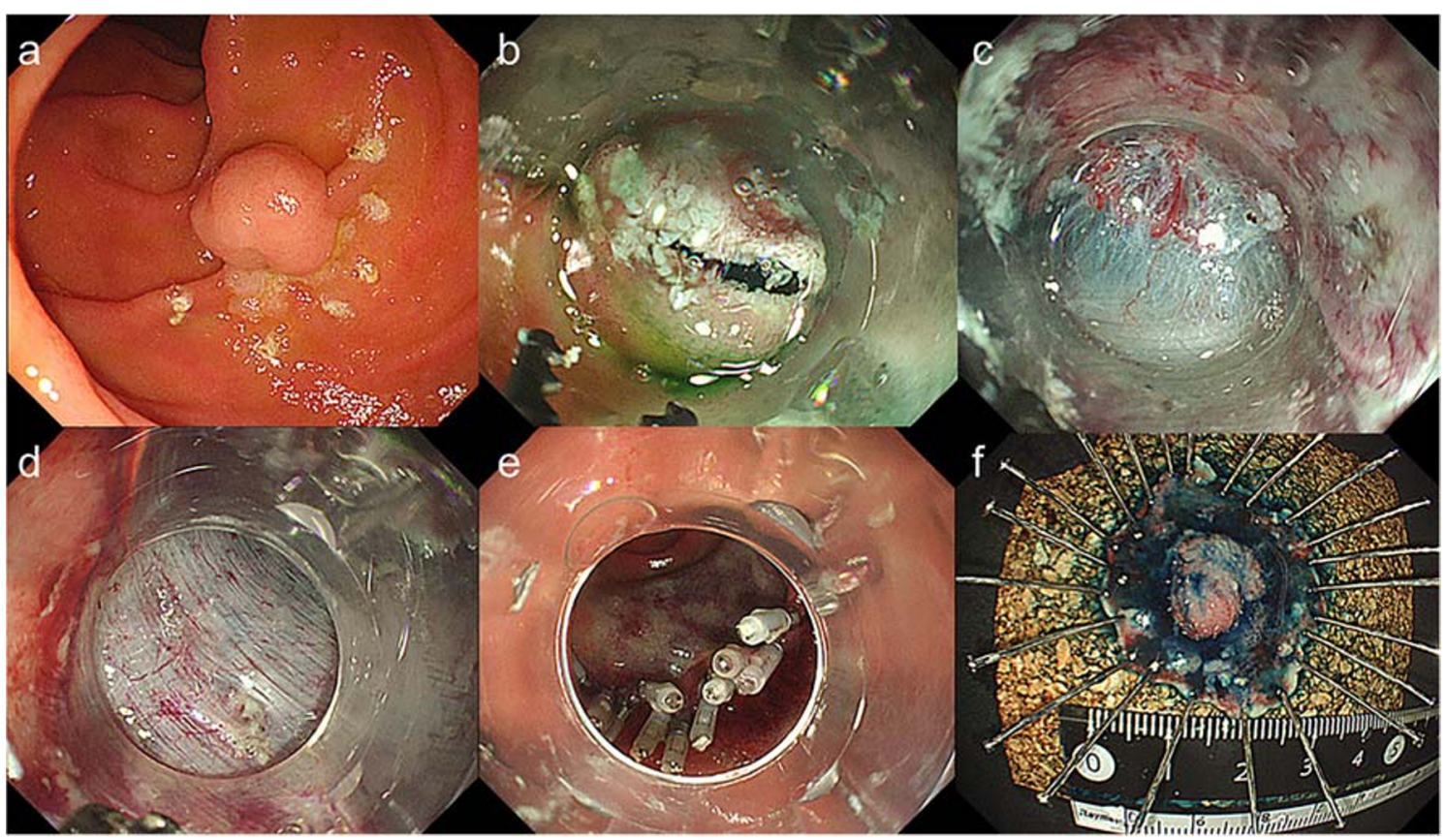

Fig. 1. Endoscopic submucosal dissection (ESD) using the short-type Clutch Cutter. a Endoscopic view of a 0-I + IIa-type tumor located in the descending duodenum. Marks are made at several points along the outline of the lesion with a forced coagulation current. $\mathbf{b}$ Endoscopic view of the mucosal incision using the short-type Clutch Cutter after submucosal injection. $\mathbf{c}$ Endoscopic view of the submucosal dissection using the short-type Clutch Cutter. The submucosal tissue being grasped, pulled, and excised from the muscle layer. $\mathbf{d}$ The lesion is removed completely from the muscle layer. e The post-ESD ulcer that has been completely closed with endoscopic clips. $\mathbf{f}$ The resected specimen shows en bloc resection of the lesion. 


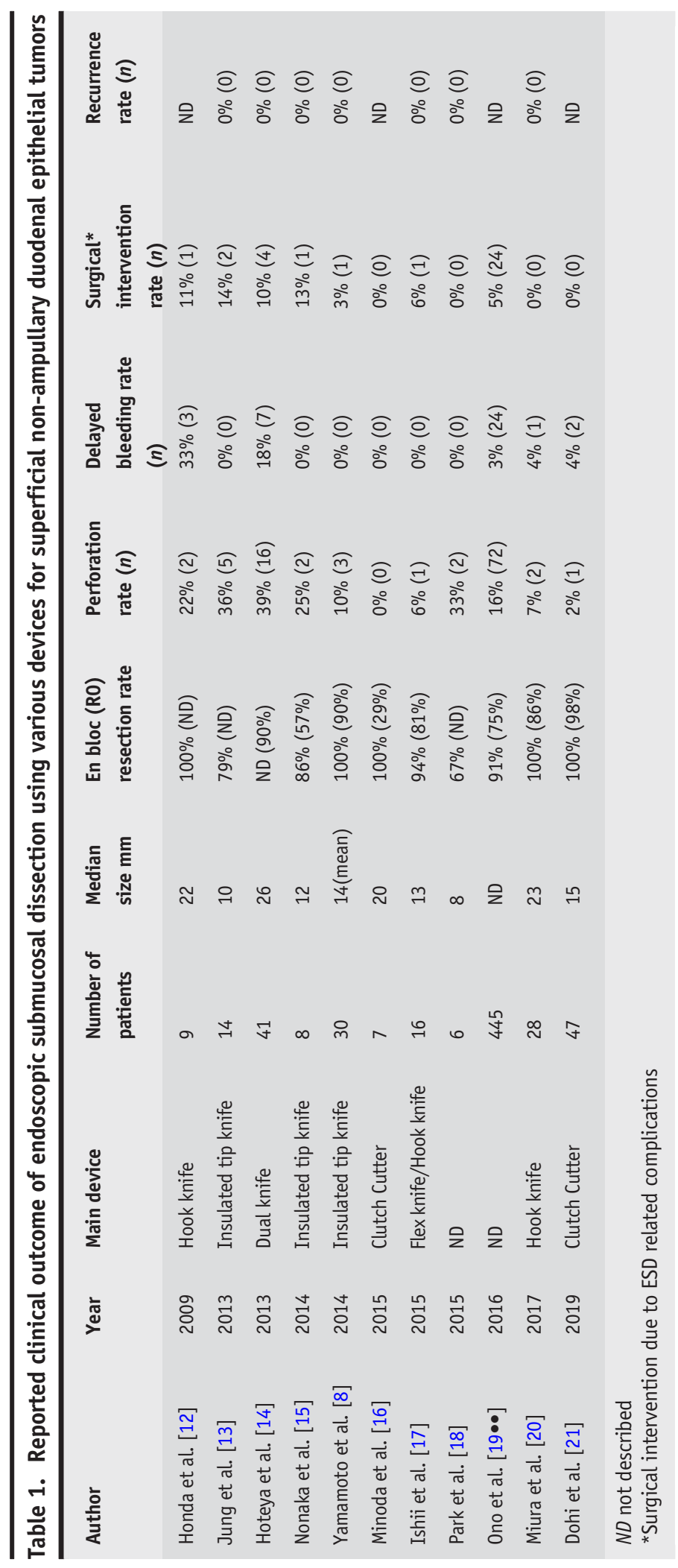


ESD is caused by anatomical and histological features of the duodenum. Anatomical problems are redundant stomach and duodenal angle, which cause poor control of the endoscope and a vertical approach to the muscularis propria during ESD. Histological problems are the presence of Brunner's glands and thin muscularis propria that lead to poor submucosal elevation after submucosal injection and easy full-thickness electric damage of the muscle layer $[4,5$, 40]. Reported intraoperative and delayed perforation rates are 19-35\% and 3$20 \%$, respectively. Incidence of delayed bleeding is reported as $0-22 \%$. [13, 14 , $19 \bullet \bullet, 41-43$ ]. The major cause of intraoperative perforation is unintentional electrothermal damage to the thin muscularis propria, probably caused by electromechanical problems of the ESD devices, coupled with poor endoscopic control and intraoperative endoscopic view. The main causes of delayed perforation and bleeding are speculated to be excessive electrocauterization of the duodenal wall caused by electromechanical problems of the ESD devices, and exposure of the ulcer base to pancreatic and bile juices, which may cause proteolysis or chemical irritation $[4,5,20,40]$.

\section{Intraoperative countermeasures for adverse events}

\section{Selection of ESD devices from the point of view of electric mechanism}

In duodenal ESD, the approach to go straight to the muscular layer is frequently taken, so the use of a conventional knife that incises while pressing lightly on the muscle layer increases the risk of perforation. Therefore, it is considered safe to perform ESD using a hook knife [17] (Fig. 2a) (KD 620LR; Olympus, Tokyo,

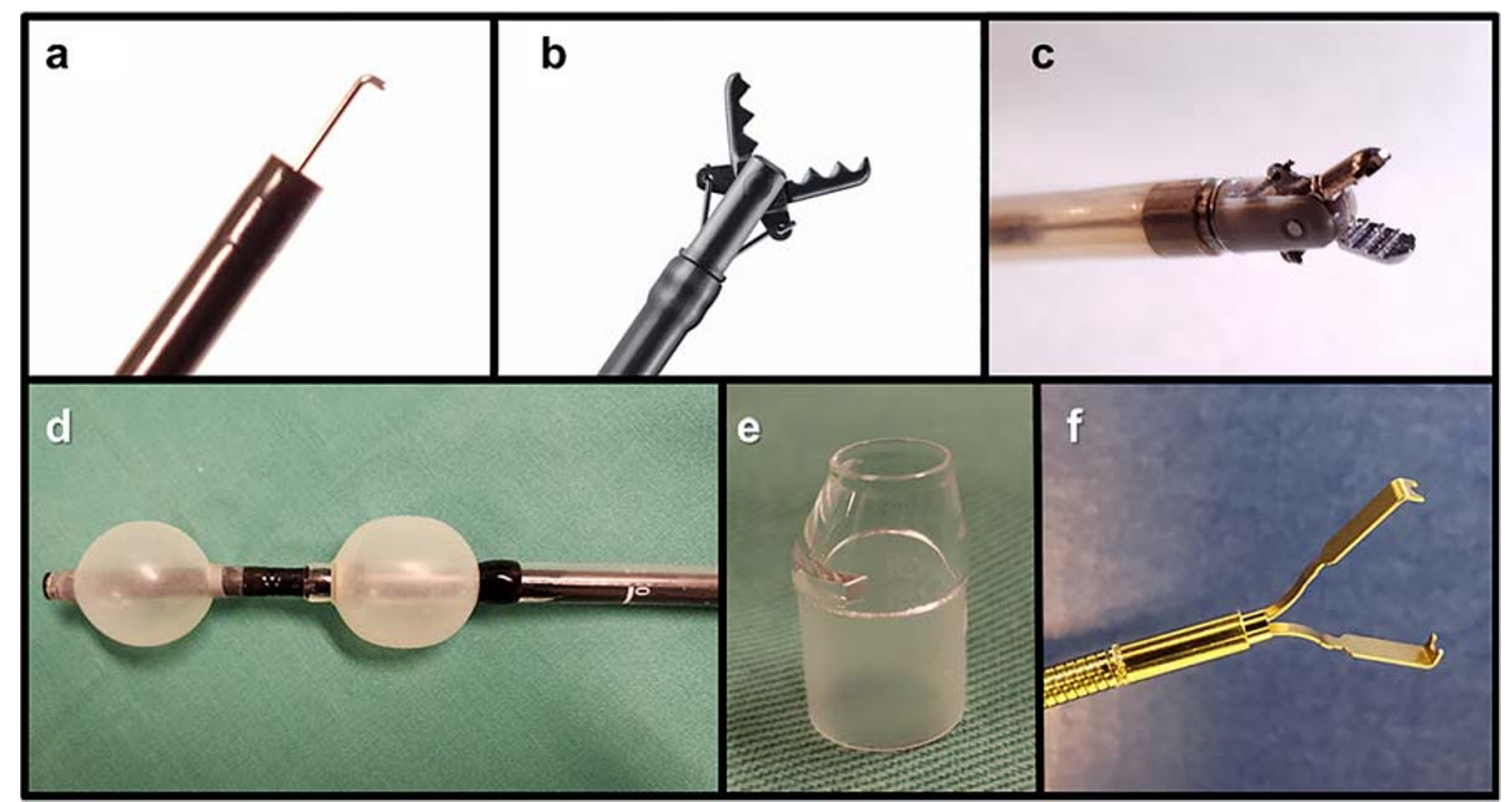

Fig. 2. Preventive endoscopic devices for adverse events associated with duodenal endoscopic submucosal dissection. a Hook knife. b Short-type Clutch Cutter (grasping-type scissors forceps). c Tighturn (bipolar hemostatic forceps). d Short-type doubleballoon endoscope. e ST hood (small-caliber-tip transparent hood). f ZEOCLIP (ZP-CL; ZEON MEDICAL, Tokyo, Japan) (single opening-and-closing clips). 
Japan) or a Clutch Cutter (grasping-type scissors forceps) [16, 38] (Fig. 2b and Video 1) (DP2618DT-35; Fujifilm, Tokyo, Japan) that can be energized and incised while pulling after hooking or grasping tissue. Since these two devices can energize the targeted tissue away from the thin muscle layer, there is a low risk of electrothermal damage to the muscle layer. Reported perforation rates of hook knife $[12,20]$ and Clutch Cutter $[16,21]$ were $7-22 \%$ and $0-4 \%$, respectively (Table 1 ). Furthermore, hemostatic coagulation for intra-ESD bleeding is another main cause of postoperative perforation. Conventional hemostatic forceps use a monopolar electrical current system and have no outside insulation. Although they have a strong coagulation effect for broad and deep tissue, their use leads to postoperative perforation. For duodenal ESD, it is desirable to use safe outer-side insulated grasping-type scissors forceps (Clutch Cutter) [16, 21] (Fig. 2b) or bipolar hemostatic forceps [44] (Fig. 2c) (Tighturn, RH7C2900; ZEON MEDICAL, Tokyo, Japan), which allow pinpoint coagulation of the bleeding artery or vein.

\section{Endoscopic approach method from the point of view of better endoscopic control}

Hayashi et al. reported the unique technique "the pocket creation method" [45] which provides us better scope control during ESD. In this method, a 2-3-cm mucosal incision is made on the endoscopic side of the lesion. This is followed by submucosal dissection of the same part to create a cavity (pocket) where there is sufficient space available for sufficient insertion and fixation of the endoscope. In the pocket space, the endoscope during ESD is stabilized in the submucosa and the endoscopic view allows for a horizontal approach to the muscularis propria layer. Miura et al. [20] reported 100\% en bloc resection rate and $4 \%$ perforation rate of duodenal ESD using this method.

Another unique approach is the use of a double-balloon endoscope. Originally, the double-balloon endoscope was developed by Yamamoto for small intestinal endoscopy [46]. The short-type double-balloon endoscopes (Fig. 2d) (EI-580BT; Fujifilm) can keep the digestive tract short. Thus, the use of doubleballoon endoscopes improves anatomical problems such as redundant stomach and duodenal angles that cause poor endoscopic control and a vertical approach to the muscularis propria layer [40]. This is a promising way to achieve accurate and safe ESD of the duodenum by stabilizing the control of the endoscope tip.

\section{Endoscopic observation method from the point of view of better intraoperative visualization}

The presence of Brunner's glands means that sufficient thickness of the submucosa cannot be obtained even after submucosal injection, so it is difficult to insert the tip of the endoscope into the submucosa after mucosal incision by ESD using a conventional hood. Therefore, submucosal excision is performed under poor endoscopic observation and this situation leads to perforation. To overcome this, the small-caliber-tip transparent (ST) hood (Fig. 2e) (Video 1) (DH-40GR; Fujifilm) is important. Since the tip of the ST hood is tapered, it can easily be inserted into the submucosa from a narrow mucosal incision, and submucosal dissection can be performed under direct endoscopic visualization. It provides adequate countertraction to the submucosal layer and good visualization of the targeted submucosa during $\operatorname{ESD}[20,40]$. 
One more unique technique is the water pressure method [47]. In this procedure, the waterjet function of the endoscope is used, and the water pressure helps insertion of the tip of the hood and provides clear vision underwater during ESD.

\section{Postoperative countermeasures for adverse events}

\section{Endoscopic closure of the post-ESD ulcer using clips}

Closure of the duodenal superficial tissue defect after ESD (Fig. 1e) is considered to be the most effective countermeasure for post-ESD perforation and delayed bleeding, because it protects against exposure of electrically damaged muscle layers to pancreatic and bile juices. Kato et al. [48] reported that a complete closure of the mucosal defect after duodenal ESD significantly decreased the number of delayed adverse events as compared with the incomplete/no closure group. Reported rates of post-ESD perforation in the complete closure and incomplete/no closure groups were $1.7 \%$ and $10.5 \%$, respectively. Reported rates of delayed bleeding in each group were $0 \%$ and $10.5 \%$, respectively. Another study showed that simple prophylactic closure using an endoclip after duodenal ESD reduces the risk of delayed bleeding [49]. Fukuhara et al. [50] reviewed 32 patients with intraoperative perforation of duodenal ESD. Those who could be completely closed had significantly shorter fasting and hospitalization periods and significantly lower maximum serum Creactive protein levels than those who could not. At present, the closure of mucosal defects after duodenal ESD using endoclips (Fig. 2f) is recognized as the most effective countermeasure for perforation and delayed bleeding of duodenal ESD.

Other methods

Over-the-scope clip

In addition to being a hemostatic device for bleeding lesions, the over-the-scope clip (OTSC) (Ovesco Endoscopy AG, Tübingen, Germany) was developed for closure of mucosal defects in patients with acute gastrointestinal perforation and anatomical leakage [51] and is used to close duodenal mucosal defects after ESD [52]. Tashima et al. [53] investigated the clinical outcome of 50 patients with prophylactic closure using OTSC after duodenal ESD. They reported a closure success rate of $94 \%$, delayed perforation rate of $2.1 \%$, and delayed bleeding rate of $6.3 \%$.

\section{Endoscopic shielding method with polyglycolic acid sheets and fibrin glue}

Polyglycolic acid (PGA) sheets and fibrin glue are commonly used to cover open wound surfaces in the surgical field [54]. Furthermore, combination of PGA sheets (Neoveil; Gunze, Osaka, Japan) and fibrin glue (Beriplast P CombiSet; CSL Behring Pharma, Tokyo, Japan) has proven effective in prevention of various adverse events after ESD in the esophagus, stomach, and colorectum [55-57]. Similarly, some case reports have shown the efficacy of shielding over ulcers after duodenal ESD [58-60]. However, a Japanese prospective multicenter randomized controlled trial (137 patients) [61] showed that the PGA shielding method did not significantly prevent post-ESD bleeding. Post-ESD 
bleeding occurred in three (4.5\% patients) in the PGA group and four (5.7\%) in the control group. There was no significant difference between the two groups. At present, this procedure may be considered when endoscopic closure using the clips is unsuccessful.

\section{LECS}

LECS was developed as a less invasive surgical procedure for gastric submucosal tumors [62]. LECS is also applied to early-stage duodenal tumors to reduce the risk of complications. In LECS for SNADETs [63], the mucosal defect after ESD is closed tightly after laparoscopic suturing of the duodenal wall from the extraluminal side. No severe adverse events have been reported for this procedure. If intra-ESD perforation occurs, it can be sutured endoscopically and laparoscopically. However, this technique needs many specialists including endoscopists, anesthesiologists, and surgeons, and costs too much. Furthermore, LECS cannot cope with lesions on the inner side of the duodenum with the pancreatic head parenchyma behind [64,65].

\section{Endoscopic nasobiliary and pancreatic duct drainage}

Pancreatic and bile juices are an important cause of delayed perforation [4, 40, 48]. Theoretically, external drainage of bile and pancreatic juices might be effective in preventing delayed perforation. The preventive efficacy of endoscopic nasobiliary and pancreatic duct drainage (ENBPD) for ulcers after duodenal ESD has only been shown in a small number of case series [50]. Furthermore, ENBPD has a risk of post-ESD ulcer perforation resulting from insertion of a side-viewing endoscope, as well as post-endoscopic retrograde cholangiopancreatography pancreatitis. The indications for ENBPD should be limited to cases in which endoscopic closure using clips is unsuccessful or impossible.

\section{Conclusion}

ESD is the only endoscopic treatment that can reliably perform R0 resection of mucosal cancer and precancerous lesions of the entire gastrointestinal tract regardless of their size or shape. At present, ESD for SNADETs is a challenge, because it has the difficulty of ESD procedures and the occurrence of serious adverse events caused by the anatomical and histological characteristics of the duodenum. However, the R0 resection rate and safety have improved because of the development of new devices and techniques. Prospective studies are necessary to determine if ESD can become a part of the standard of care for SNADETs.

\section{Acknowledgments}

We thank Cathel Kerr, BSc, PhD, from Edanz Group (www.edanzediting.com/ac) and Christopher Wade from the education promotion office of Aso lizuka Hospital for editing a draft of this manuscript. 


\section{Compliance with Ethical Standards}

\section{Conflict of Interest}

Kazuya Akahoshi and FUJIFILM have applied for the patent for the Clutch Cutter described in this article. Japan, China, and the EU have already granted the patent. Masaru Kubokawa declares that he has no conflict of interest. Kazuki Inamura declares that he has no conflict of interest. Kazuaki Akahoshi declares that he has no conflict of interest. Yuki Shiratsuchi declares that he has no conflict of interest. Shinichi Tamura declares that he has no conflict of interest.

\section{Open Access}

This article is licensed under a Creative Commons Attribution 4.0 International License, which permits use, sharing, adaptation, distribution and reproduction in any medium or format, as long as you give appropriate credit to the original author(s) and the source, provide a link to the Creative Commons licence, and indicate if changes were made. The images or other third party material in this article are included in the article's Creative Commons licence, unless indicated otherwise in a credit line to the material. If material is not included in the article's Creative Commons licence and your intended use is not permitted by statutory regulation or exceeds the permitted use, you will need to obtain permission directly from the copyright holder. To view a copy of this licence, visit http://creativecommons.org/licenses/by/4.0/.

\section{References and Recommended Reading}

Papers of particular interest, published recently, have been highlighted as:

- Of importance

$\bullet \quad$ Of major importance

1. Goda K, Kikuchi D, Yamamoto Y, Takimoto K, Kakushima N, Morita Y, et al. Endoscopic diagnosis of superficial non-ampullary duodenal epithelial tumors in Japan: multicenter case series. Dig Endosc. 2014;26(suppl 2):23-9. https://doi.org/10.1111/den. 12277

A large Japanese multicenter retrospective study of endoscopic diagnosis for SNADETs.

2. Toba T, Inoshita N, Kaise M, Nomura K, Kuribayashi Y, Tanaka M, et al. Clinicopathological features of superficial non-ampurally duodenal epithelial tumor; gastric phenotype of histology correlates to higher malignant potency. J Gastroenterol. 2018;53:64-70. https://doi. org/10.1007/s00535-017-1327-0.

3. Kakushima N, Kanemoto H, Sasaki K, Kawata N, Tanaka M, Takizawa $K$, et al. Endoscopic and biopsy diagnoses of superficial, nonampullary, duodenal adenocarcinomas. World J Gastroenterol. 2015;21:55607. https://doi.org/10.3748/wjg.v21.i18.5560.

4. Ochiai Y, Kato M, Kiguchi Y, Akimoto T, Nakayama A, Sasaki M, et al. Current status and challenges of endoscopic treatments for duodenal tumors. Digestion. 2019;99:21-6. https://doi.org/10.1159/ 000494408.

5. Esaki M, Suzuki S, Ikehara H, Kusano C, Gotoda T. Endoscopic diagnosis and treatment of superficial nonampullary duodenal tumors. World J Gastrointest Endosc. 2018;10:156-64. https://doi.org/10.4253/ wjge.v10.i9.156.

6. Maruoka D, Arai M, Kishimoto T, Matsumura T, Inoue M, Nakagawa T, et al. Clinical outcomes of endoscopic resection for nonampullary duodenal high-grade dysplasia and intramucosal carcinoma. Endoscopy. 2013;45:138-41. https://doi.org/10.1055/s-00321325799.

7. Apel D, Jakobs R, Spiethoff A, Riemann JF. Follow-up after endoscopic snare resection of duodenal adenomas. Endoscopy. 2005;37:444-8. https://doi.org/10. 1055/s-2005-861287.

8. Yamamoto Y, Yoshizawa N, Tomida H, Fujisaki J, Igarashi M. Therapeutic outcomes of endoscopic resection for superficial non-ampullary duodenal tumor. 
Dig Endosc. 2014;26(Suppl 2):50-6. https://doi.org/ 10.1111/den.12273.

9. Abbass R, Rigaux J, Al-Kawas FH. Nonampullary duodenal polyps: characteristics and endoscopic management. Gastrointest Endosc. 2010;71:754-9. https:// doi.org/10.1016/j.gie.2009.11.043.

10. Klein A, Nayyar D, Bahin FF, Qi Z, Lee E, Williams SJ, et al. Endoscopic mucosal resection of large and giant lateral spreading lesions of the duodenum: success, adverse events, and long-term outcomes. Gastrointest Endosc. 2016;84:688-96. https://doi.org/10.1016/j. gie.2016.02.049.

11. Inoue T, Uedo $\mathrm{N}$, Yamashina $\mathrm{T}$, Yamamoto S, Hanaoka $\mathrm{N}$, Takeuchi Y, et al. Delayed perforation: a hazardous complication of endoscopic resection for nonampullary duodenal neoplasm. Dig Endosc. 2014;26:220-7. https://doi.org/10.1111/den.12104.

12. Honda T, Yamamoto H, Osawa H, Yoshizawa M, Nakano H, Sunada K, et al. Endoscopic submucosal dissection for superficial duodenal neoplasms. Dig Endosc. 2009;21:270-4. https://doi.org/10.1111/j. 1443-1661.2009.00908.x.

13. Jung JH, Choi KD, Ahn JY, Lee JH, Jung HY, Choi KS, et al. Endoscopic submucosal dissection for sessile, nonampullary duodenal adenomas. Endoscopy. 2013;45:133-5. https://doi.org/10.1055/s-00321326178.

14. Hoteya S, Yahagi N, Iizuka T, Kikuchi D, Mitani T, Matsui A, et al. Endoscopic submucosal dissection for nonampullary large superficial adenocarcinoma/ adenoma of the duodenum: feasibility and long-term outcomes. Endosc Int Open. 2013;1:2-7. https://doi. org/10.1055/s-0033-1359232.

15. Nonaka S, Oda I, Tada K, Mori G, Sato Y, Abe S, et al. Clinical outcome of endoscopic resection for nonampullary duodenal tumors. Endoscopy. 2015;47:129-35. https://doi.org/10.1055/s-00341390774.

16. Minoda Y, Akahoshi K, Otsuka Y, Kubokawa M, Motomura Y, Oya M, et al. Endoscopic submucosal dissection of early duodenal tumor using the Clutch Cutter: a preliminary clinical study. Endoscopy. 2015;47 (Suppl 1) UCTN:E267-8. https://doi.org/10. 1055/s-0034-1392209.

17. Ishii N, Akiyama H, Suzuki K, Fujita Y. Safety and efficacy of endoscopic submucosal dissection for nonampullary duodenal neoplasms: a case series. ACG Case Rep J. 2015;2:146-9. https://doi.org/10.14309/ crj.2015.36.

18. Park SM, Ham JH, Kim BW, Kim JS, Kim CW, Kim JI, et al. Feasibility of endoscopic resection for sessile nonampullary duodenal tumors: a multicenter retrospective study. Gastroenterol Res Pract.

2015;2015:692492-4. https://doi.org/10.1155/2015/ 692492.

19.• Ono H, Kaise M, Nonaka S, Uedo N, Hirasawa T, Oyama T, et al. Clinical issues of duodenal endoscopic treatment. (in Japanese with English abstract). Stomach Intestine. 2016;51:1585-92
A large Japanese multicenter retrospective study of endoscopic resection for SNADETs.

20. Miura Y, Shinozaki S, Hayashi Y, Sakamoto H, Lefor AK, Yamamoto H. Duodenal endoscopic submucosal dissection is feasible using the pocket-creation method. Endoscopy. 2017;49:8-14. https://doi.org/10.1055/s0042-116315.

21. Dohi O, Yoshida N, Naito Y, et al. Efficacy and safety of endoscopic submucosal dissection using a scissors-type knife with prophylactic over-the-scope clip closure for superficial non-ampullary duodenal epithelial tumors. Dig Endosc. 2019. https://doi.org/10.1111/den.13618 Online ahead of print.

22. Endo M, Abiko Y, Oana S, Kudara N, Chiba T, Suzuki $\mathrm{K}$, et al. Usefulness of endoscopic treatment for duodenal adenoma. Dig Endosc. 2010;22:360-5. https:// doi.org/10.1111/j.1443-1661.2010.01014.x.

23. Alwmark A, Andersson A, Lasson A. Primary carcinoma of the duodenum. Ann Surg. 1980;191:13-8. https:// doi.org/10.1097/00000658-198001000-00003.

24. Jepsen JM, Persson M, Jakobsen NO, Christiansen T, Skoubo-Kristensen E, Funch-Jensen $\mathrm{P}$, et al. Prospective study of prevalence and endoscopic and histopathologic characteristics of duodenal polyps in patients submitted to upper endoscopy. Scand J Gastroenterol. 1994;29:483-7. https://doi.org/10.3109/ 00365529409092458.

25. Schottenfeld D, Beebe-Dimmer JL, Vigneau FD. The epidemiology and pathogenesis of neoplasia in the small intestine. Ann Epidemiol. 2009;19:58-69. https://doi.org/10.1016/j.annepidem.2008.10.004.

26. van Heumen BW, Mul K, Nagtegaal ID, van Kouwen MC, Nagengast FM. Management of sporadic duodenal adenomas and the association with colorectal neoplasms: a retrospective cohort study. J Clin Gastroenterol. 2012;46:390-6. https://doi.org/10. 1097/MCG.0b013e318238e72d.

27. van Heumen BW, Nieuwenhuis $M H$, van Goor $H$, Mathus-Vliegen LE, Dekker E, Gouma DJ, et al. Surgical management for advanced duodenal adenomatosis and duodenal cancer in Dutch patients with familial adenomatous polyposis: a nationwide retrospective cohort study. Surgery. 2012;151:681-90. https://doi. org/10.1016/j.surg.2011.12.008.

28. Lee CHA, Shingler G, Mowbray NG, Al-Sarireh B, Evans $\mathrm{P}$, Smith M, et al. Surgical outcomes for duodenal adenoma and adenocarcinoma: a multicentre study in Australia and the United Kingdom. ANZ J Surg. 2018;88:E157-61. https://doi.org/10.1111/ans. 13873.

29. Hara Y, Goda K, Dobashi A, Ohya TR, Kato M, Sumiyama K, et al. Short- and long-term outcomes of endoscopically treated superficial non-ampullary duodenal epithelial tumors. World J Gastroenterol. 2019;25:707-18. https://doi.org/10.3748/wjg.v25.i6. 707.

30. Maruoka D, Matsumura T, Kasamatsu S, Ishigami H, Taida T, Okimoto K, et al. Cold polypectomy for duodenal adenomas: a prospective clinical trial. 
Endoscopy. 2017;49:776-83. https://doi.org/10.1055/ s-0043-107028.

31. Binmoeller KF, Shah JN, Bhat YM, Kane SD. "Underwater" EMR of sporadic laterally spreading nonampullary duodenal adenomas (with video). Gastrointest Endosc. 2013;78:496-502. https://doi. org/10.1016/j.gie.2013.03.1330.

32. Yamasaki Y, Uedo N, Takeuchi Y, Higashino K, Hanaoka N, Akasaka T, et al. Underwater endoscopic mucosal resection for superficial nonampullary duodenal adenomas. Endoscopy. 2018;50:154-8. https:// doi.org/10.1055/s-0043-119214.

33. Nishizawa T, Yahagi N. Endoscopic mucosal resection and endoscopic submucosal dissection: technique and new directions. Curr Opin Gastroenterol. 2017;33:315-9. https://doi.org/10.1097/MOG. 0000000000000388 .

34. Akahoshi K, Minoda Y, Komori K, Motomura Y, Kubokawa M, Otsuka Y, et al. Endoscopic submucosal dissection using the "Clutch Cutter" for early esophageal squamous cell carcinoma. Endoscopy. 2013;45:1035-8. https://doi.org/10.1055/s-00331344863.

35. Tanabe S, Ishido K, Higuchi K, Sasaki T, Katada C, Azuma M, et al. Long-term outcomes of endoscopic submucosal dissection for early gastric cancer: a retrospective comparison with conventional endoscopic resection in a single center. Gastric Cancer.

2014;17:130-6. https://doi.org/10.1007/s10120-0130241-2.

36. Akahoshi K, Motomura Y, Kubokawa M, Gibo J, Kinoshita N, Osada S, et al. Endoscopic submucosal dissection for early gastric cancer using the Clutch Cutter: a large single-center experience. Endosc Int Open. 2015;3:E432-8. https://doi.org/10.1055/s0034-1392509.

37. Komori K, Akahoshi K, Kubokawa M, Motomura Y, Oya M, Ihara E, et al. Endoscopic submucosal dissection for rectal carcinoid tumour using the Clutch Cutter. ANZ J Surg. 2014;84:847-51. https://doi.org/10. 1111/ans.12643.

38. Akahoshi K, Shiratsuchi Y, Oya M, Koga H, Kubokawa M, Nakama N, et al. Endoscopic submucosal dissection with a grasping-type scissors for early colorectal epithelial neoplasms: a large single-center experience. VideoGIE. 2019;4:486-92. https://doi.org/10.1016/j. vgie.2019.05.003

39. Matsumoto S, Yoshida Y. Selection of appropriate endoscopic therapies for duodenal tumors: an open-label study, single-center experience. World J Gastroenterol. 2014;20:8624-30. https://doi.org/10.3748/wjg.v20. i26.8624.

40. Yamamoto H, Miura Y. Duodenal ESD: conquering difficulties. Gastrointest Endosc Clin N Am. 2014;24:235-44. https://doi.org/10.1016/j.giec.2013. 11.007 .

41. Kakushima N, Ono H, Takao T, Kanemoto H, Sasaki K. Method and timing of resection of superficial nonampullary duodenal epithelial tumors. Dig
Endosc. 2014;26(suppl 2):35-40. https://doi.org/10. 1111/den.12259.

42. Hoteya S, Furuhata T, Takahito T, Fukuma Y, Suzuki Y, Kikuchi D, et al. Endoscopic submucosal dissection and endoscopic mucosal resection for non-ampullary superficial duodenal tumor. Digestion. 2017;95:3642. https://doi.org/10.1159/000452363.

43. Matsumoto S, Miyatani H, Yoshida Y. Endoscopic submucosal dissection for duodenal tumors: a singlecenter experience. Endoscopy. 2013;45:136-7. https:// doi.org/10.1055/s-0032-1310123.

44. Kataoka M, Kawai T, Yagi K, Tachibana C, Tachibana H, Sugimoto $\mathrm{H}$, et al. Clinical evaluation of emergency endoscopic hemostasis with bipolar forceps in nonvariceal upper gastrointestinal bleeding. Dig Endosc. 2010;22:151-5. https://doi.org/10.1111/j.1443-1661. 2010.00949.x.

45. Hayashi Y, Miura Y, Yamamoto H. Pocket-creation method for the safe, reliable, and efficient endoscopic submucosal dissection of colorectal lateral spreading tumors. Dig Endosc. 2015;27:534-5. https://doi.org/ 10.1111/den.12465.

46. Yamamoto H, Kita H, Sunada K, Hayashi Y, Sato H, Yano T, et al. Clinical outcomes of double-balloon endoscopy for the diagnosis and treatment of smallintestinal diseases. Clin Gastroenterol Hepatol. 2004;2:1010-6. https://doi.org/10.1016/s15423565(04)00453-7.

47. Yahagi N, Nishizawa T, Sasaki M, Ochiai Y, Uraoka T. Water pressure method for duodenal endoscopic submucosal dissection. Endoscopy. 2017;49:E227-8. https://doi.org/10.1055/s-0043-113556.

48. Kato M, Ochiai Y, Fukuhara S, Maehata T, Sasaki M, Kiguchi $Y$, et al. Clinical impact of closure of the mucosal defect after duodenal endoscopic submucosal dissection. Gastrointest Endosc. 2019;89:87-93. https://doi.org/10.1016/j.gie.2018.07.026.

49. Hoteya S, Kaise M, Iizuka T, Ogawa O, Mitani T, Matsui A, et al. Delayed bleeding after endoscopic submucosal dissection for non-ampullary superficial duodenal neoplasias might be prevented by prophylactic endoscopic closure: analysis of risk factors. Dig Endosc. 2015;27:323-30. https://doi.org/10.1111/den.12377.

50. Fukuhara S, Kato M, Iwasaki E, Sasaki M, Tsutsumi K, Kiguchi $Y$, et al. Management of perforation related to endoscopic submucosal dissection for superficial duodenal epithelial tumors. Gastrointest Endosc. 2019. https://doi.org/10.1016/j.gie.2019.09.024.

51. Mangiavillano B, Caruso A, Manta R, Di Mitri R, Arezzo A, Pagano N, et al. Over-the-scope clips in the treatment of gastrointestinal tract iatrogenic perforation: a multicenter retrospective study and a classification of gastrointestinal tract perforations. World J Gastrointest Surg. 2016;8:315-20. https://doi.org/10.4240/wigs.v8. i4.315.

52. Nishiyama N, Mori H, Kobara H, Rafiq K, Fujihara S, Kobayashi M, et al. Efficacy and safety of over-thescope clip: including complications after endoscopic submucosal dissection. World J Gastroenterol. 
2013;19:2752-60. https://doi.org/10.3748/wjg.v19. i18.2752.

53. Tashima T, Ohata K, Sakai E, Misumi Y, Takita M, Minato Y, et al. Efficacy of an over-the-scope clip for preventing adverse events after duodenal endoscopic submucosal dissection: a prospective interventional study. Endoscopy. 2018;50:487-96. https://doi.org/ 10.1055/s-0044-102255.

54. Kawai H, Harada K, Ohta H, Tokushima T, Oka S. Prevention of alveolar air leakage after video-assisted thoracic surgery: comparison of the efficacy of methods involving the use of fibrin glue. Thorac Cardiovasc Surg. 2012;60:351-5. https://doi.org/10.1055/s-00311293599 .

55. Tsuji Y, Fujishiro M, Kodashima S, Ono S, Niimi K, Mochizuki S, et al. Polyglycolic acid sheets and fibrin glue decrease the risk of bleeding after endoscopic submucosal dissection of gastric neoplasms (with video). Gastrointest Endosc. 2015;81:906-12. https://doi. org/10.1016/j.gie.2014.08.028.

56. Sakaguchi Y, Tsuji Y, Ono S, Saito I, Kataoka Y, Takahashi Y, et al. Polyglycolic acid sheets with fibrin glue can prevent esophageal stricture after endoscopic submucosal dissection. Endoscopy. 2015;47:336-40. https://doi.org/10.1055/s-0034-1390787.

57. Tsuji Y, Ohata K, Gunji T, Shozushima M, Hamanaka J, Ohno A, et al. Endoscopic tissue shielding method with polyglycolic acid sheets and fibrin glue to cover wounds after colorectal endoscopic submucosal dissection (with video). Gastrointest Endosc.

2014;79:151-5. https://doi.org/10.1016/j.gie.2013. 08.041 .

58. Takimoto K, Imai Y, Matsuyama K. Endoscopic tissue shielding method with polyglycolic acid sheets and fibrin glue to prevent delayed perforation after duodenal endoscopic submucosal dissection. Dig Endosc. 2014;26(Suppl 2):46-9. https://doi.org/10.1111/den. 12280.

59. Doyama H, Tominaga K, Yoshida N, Takemura K, Yamada S. Endoscopic tissue shielding with polyglycolic acid sheets, fibrin glue and clips to prevent delayed perforation after duodenal endoscopic resection. Dig Endosc. 2014;26(Suppl 2):41-5. https://doi. org/10.1111/den.12253.
60. Takimoto K, Toyonaga T, Matsuyama K. Endoscopic tissue shielding to prevent delayed perforation associated with endoscopic submucosal dissection for duodenal neoplasms. Endoscopy. 2012;44 (Suppl 2) UCTN:E414-5. https://doi.org/10.1055/s-00321325739.

61. Kataoka Y, Tsuji Y, Hirasawa K, Takimoto K, Wada T, Mochizuki S, et al. Endoscopic tissue shielding to prevent bleeding after endoscopic submucosal dissection: a prospective multicenter randomized controlled trial. Endoscopy. 2019;51:619-27. https://doi.org/10.1055/ a-0860-5280.

62. Hiki N, Yamamoto Y, Fukunaga T, Yamaguchi T, Nunobe S, Tokunaga M, et al. Laparoscopic and endoscopic cooperative surgery for gastrointestinal stromal tumor dissection. Surg Endosc. 2008;22:1729-35. https://doi.org/10.1007/s00464-007-9696-8.

63. Otowa Y, Kanaji S, Morita Y, Suzuki S, Yamamoto M, Matsuda Y, et al. Safe management of laparoscopic endoscopic cooperative surgery for superficial nonampullary duodenal epithelial tumors. Endosc Int Open. 2017;5:E1153-8. https://doi.org/10.1055/s0043-117957.

64. Poudel S, Ebihara Y, Tanaka K, Kurashima Y, Murakami S, Shichinohe T, et al. Two cases of laparoscopic direct spiral closure of large defects in the second portion of the duodenum after laparoscopic endoscopic co-operative surgery. J Minim Access Surg. 2018;14:149-53. https://doi.org/10.4103/jmas.

65. Ohata K, Murakami M, Yamazaki K, Nonaka K, Misumi N, Tashima T, et al. Feasibility of endoscopyassisted laparoscopic full-thickness resection for superficial duodenal neoplasms. Sci World J. 2014;2014:239627-6. https://doi.org/10.1155/2014/ 239627.

\section{Publisher's Note}

Springer Nature remains neutral with regard to jurisdictional claims in published maps and institutional affiliations. 